\title{
A diplomacia universalista do Brasil: a construção do sistema contemporâneo de relações bilaterais
}

\author{
ANTÔNIO CARLOS LESSA*
}

\section{Introdução}

A lenta e gradual constituição de um impressionante acervo de contatos bilaterais é dos patrimônios mais sólidos da política exterior do Brasil. A diversidade desses contatos, espalhados pelos cinco continentes, expressos em laços mais ou menos efetivos entre sociedades aproximadas por circunstâncias políticas, econômicas e culturais, serviu em diversos momentos à sociedade brasileira para a realização de seu interesse nacional.

Considerando-se a multiplicidade de tal acervo, proceder ao seu inventário seria empresa de pouca valia, uma vez que permaneceriam escondidas, sob os atos dos homens de Estado, a riqueza e a efetividade de muitos relacionamentos bilaterais pautados pelo dinamismo social - além do que, uma já substantiva bibliografia (apesar de ainda lacunar) está a disposição dos interessados em percorrer conceitualmente as principais vinculações bilaterais do Brasil ${ }^{1}$.

Propõe-se, portanto, uma inversão de ótica para a apropriação do sistema de relações bilaterais do Brasil: em lugar de uma averiguação pontual de parcelas do grande mosaico em vias de consecução, o que eventualmente poderia se dar por regiões ou países, adote-se como objetivo vislumbrar a obra em sua totalidade, ou seja, o universalismo que, juntamente com o pacifismo, o juridicismo e o realismo, constitui a moldura conceitual da praxis diplomática brasileira.

Assim, o presente trabalho tem por objetivo examinar as linhas gerais do processo de construção do universalismo enquanto vetor da política exterior do Brasil, processo tal que encontra na adjetivação proporcionada pela seletividade ao longo das últimas décadas, um novo modo de proporcionar instrumentalidade ao sistema de relações bilaterais do Brasil, concretizado na construção de parcerias estratégicas. 


\section{As parcerias estratégicas do Brasil: em busca de um conceito mínimo}

É certo que o desenvolvimento econômico pode ser entendido como a resultante da percepção do interesse nacional que orienta a atuação internacional do Brasil desde a década de 1930. Em diferentes momentos da história contemporânea, essa leitura se concretizou na perseguição de cinco objetivos básicos:

a) a perseguição, no plano internacional, dos elementos tidos como indispensáveis à leitura do projeto de desenvolvimento econômico em vias de implementação, sejam eles investimentos, mercados, tecnologias, fontes de energia ou empréstimos;

b) a concertação internacional, nos fóruns em que se fizer possível, para a construção de regras que desimpedissem o acesso aos insumos para o desenvolvimento;

c) a diversificação dos contatos internacionais, esconjurando a "maldição das relações especiais" com os EUA, com o que se entende os apertos nas margens de decisão e de autonomia internacional proporcionados pelos alinhamentos;

d) a integração eficaz nos fluxos econômicos internacionais;

e) a construção de uma presença internacional própria, não-alinhada e crescentemente desvinculada dos constrangimentos ideológicos do momento, sem que com isso se negue o escopo civilizacional ocidental;

Assim, uma vez que toda a conduta externa do país pauta-se pela perseguição dessas finalidades, pode-se supor que todo o conjunto de interações do Brasil com o exterior são efetivamente utilizadas pela diplomacia como instrumento para a sua consecução. A observação do sistema de relações bilaterais do Brasil confere relevo à vocação para a universalidade, que encontra origens no fato de que, em maior ou menor medida, logrou-se o estabelecimento de relações pacíficas e instrumentalizáveis com países situados em todos os continentes.

Daí decorre, portanto, que a atuação internacional do Brasil tem se caracterizado, desde o fim da II Guerra Mundial, pela construção paulatina do universalismo, processo que atingiu o seu apogeu na década de setenta, significando, historicamente, a acumulação de um certo capital de prestígio e a constituição de uma margem mínima extra de liberdade de manobra, a ser utilizada em momentos críticos. Conjugada a uma boa dose de habilidade e capacidade de articulação dos interesses que se manifestam nas relações entre duas nações, a instrumentalização do universalismo age para reforçar os ganhos internacionais. Quando foi plenamente atingido, ou melhor, quando teve a sua construção concluída, o universalismo passava a proporcionar uma maior complexidade e densidade nas relações com as potências ocidentais (EUA, Europa Ocidental e Japão), e a abertura de novos espaços na África, na Ásia e Oriente Médio. 
Sendo entendida como fator de ampliação da liberdade diplomática, a construção do universalismo, desde os seus primórdios, foi temperada por boa dose de pragmatismo, outro elemento característico da praxis diplomática brasileira e fundamental para a compreensão da Política Exterior do Brasil no século XX. Versão contemporânea do realismo em política exterior, este presente na história brasileira desde o Império, o pragmatismo tem induzido a uma eficiente adequação dos interesses nacionais aos constrangimentos internacionais ${ }^{2}$.

O pragmatismo permitiu a compatibilização da universalidade em construção com a capacidade de articulação concreta, de modo a tornar operacional o impressionante acervo de relações bilaterais em vias de acumulação. Muito cedo, portanto, agrega-se ao universalismo uma variável de seletividade que se concretiza na definição de relações prioritárias com determinados países e regiões, através da barganha em diversos movimentos: por vezes, oferece-se como trunfos a renovação do diálogo e a aproximação de posições políticas, em outras, oportunidades de grandes projetos conjuntos e a penetração comercial recíproca; espera-se, sempre em troca, insumos para o projeto de desenvolvimento em implementação, seja qual for a leitura que lhe dê o governo de plantão ${ }^{3}$.

O universalismo seletivo resultante desta visão pragmática de formulação e implementação da Política Exterior tem permitido a escolha de parceiros preferenciais, aos quais se atribui atenção diplomática privilegiada, com o objetivo de lhes conferir densidade política e econômica, o que permitiria a auferição de ganhos concretos de lado a lado. Este movimento, recorrente na história da política exterior do Brasil, pode ser conceituado como construção de Parcerias Estratégicas, que são relações políticas e econômicas prioritárias reciprocamente remuneradoras, constituídas a partir de um patrimônio de relações bilaterais universalmente configurado. A construção de parcerias estratégicas é fruto da compatibilização da vocação histórica do Brasil para a universalidade com a necessidade de aproximações seletivas, o que abre a possibilidade para movimentos de adaptação aos nichos de oportunidade e aos constrangimentos internacionais que se apresentam conjunturalmente.

\section{Da qualificação acessória à qualificação principal: a universalidade seletiva de 1958 a nossos dias}

Apesar de se trabalhar permanentemente para a preparação de vínculos alternativos que proporcionem ganhos crescentes na cena internacional, as parcerias estratégicas não se manifestam sempre, mas tornam-se operacionais apenas em determinadas conjunturas. Portanto, do ponto de vista da manifestação dessas formas “dinamizadas” de relações bilaterais, seria possível identificar dois grandes momentos, que guardam em comum a essência do movimento, mas distinguem-se na qualificação, do ponto de vista das linhas gerais da Política Exterior do Brasil, de que se reveste o universalismo seletivo: 


\subsection{A universalidade como válvula de escape}

O primeiro momento se estenderia do pós-guerra ao início da década de 1990, e encerra a instrumentalidade inerente a uma verdadeira válvula de escape, o que pode perfeitamente adjetivar a seletividade nas afirmações de vínculos forjados nos apertos das margens de manobras.

Assim, criam-se condições para o estreitamento conjuntural de vínculos com determinadas nações ou regiões, conforme se verificava apertos nas margens decisórias, inflingidos por dinâmicas próprias do sistema internacional (como o choque do petróleo de 1973, por exemplo), ou quando a forma dos relacionamentos tradicionais não bastava para continuar provendo os insumos para o desenvolvimento, ou ainda quando a deterioração das relações políticas e econômicas com a potência hegemônica impunha a criação urgente de alternativas que proporcionassem maiores margens de autonomia.

Esse período é pródigo de exemplos de construções de parcerias estratégicas, que visavam a ampliação do poder de barganha com vistas a enfrentar, no plano político e econômico, situações de exacerbação da competição por recursos e influência. Para tanto, o Brasil soube eleger projetos e buscar parceiros para a sua realização, que eram flexíveis e poderiam variar de um tema a outro.

É verdade que, nesta quadra, o movimento de construção de parcerias estratégicas é essencialmente "reativo" - pauta-se pela necessidade de expiar definitivamente o pecado original da excessiva vinculação aos desígnios norteamericanos, historicamente conformada na simbologia (e na efetividade) da expressão "relações especiais", herança dos tempos de Rio Branco que transformou-se, pelas mãos da diplomacia brasileira do pós-segunda guerra, em maldição lançada sobre o futuro da nação. Oscilando entre o alinhamento automático e o alinhamento pragmático, as relações com os EUA constituem vetor dos mais importantes da Política Exterior do Brasil, uma vez que contingenciava, em grandes linhas, a obtenção de respostas mais efetivas aos problemas financeiros, comerciais, tecnológicos e energéticos que estrangulavam o desenvolvimento econômico ${ }^{4}$.

A conformação de parcerias estratégicas beneficia-se, pois, da constatação da dependência excessiva com relação aos EUA, e do ressurgimento, na cena internacional, de atores que poderiam oferecer alternativas a esse relacionamento. A idéia de que pode passar a prescindir dos EUA torna-se clara aos brasileiros com a conclusão do processo de reconstrução das economias européias e japonesa, e já é instrumentalizada, em maior ou menor escala, pelo governo Kubitschek e pelos que lhes sucedem até o golpe de 1964.

A dinamização das relações econômicas com a Europa Ocidental durante o quinquênio JK é processo balizado pelo surto desenvolvimentista característico do momento, o que aumenta substantivamente a capacidade brasileira 
de atração de capitais estrangeiros. A Diplomacia para o Desenvolvimento é marcada pela criação do Mercado Comum Europeu, que apesar de ser imediatamente identificado pela chancelaria brasileira como um fator de constrangimento para a inserção comercial do país, presta um serviço à nação ao permitir um desvio dos fluxos de investimentos europeus para fora do continente ${ }^{5}$. Acrescem outras iniciativas diplomáticas brasileiras, permitidas pelo sentimento de maior segurança (e a certeza de que existiam alternativas) nas relações com os EUA, tal como a Operação Pan-Americana, que redimensiona a base regional de atuação do Brasil ${ }^{6}$.

A Política Externa Independente é uma radicalização, pelo menos no nível do discurso, da idéia de que outros espaços se faziam necessários para a afirmação da estratégia de obter insumos para o desenvolvimento brasileiro. A abertura para a África e para a Europa centro-oriental inscrevem-se neste movimento ${ }^{7}$.

Está claro que o governo Castelo Branco representa uma ruptura pontual e de curto fôlego neste processo de afastamento dos EUA e de gradativa instrumentalização das relações com outros parceiros. Entretanto, a Diplomacia da Prosperidade de Costa e Silva retoma timidamente, e certamente em outros termos e em novas condições históricas, a Política Externa Independente de Jânio Quadros e João Goulart. Pautava-se, pois, pela reivindicação da revisão das bases do relacionamento entre EUA e a América Latina, à medida em que aspirava definir sua própria identidade nacional como "potência emergente" capitalista em expansão. Procede-se, assim, ao afastamento das pautas ideológicas que orientaram a inserção internacional sob Castelo Branco, reassumindo-se uma atitude de relativa confrontação com a potência hegemônica e de ativa solidariedade com as reivindicações do Terceiro Mundo. A Política Exterior busca a ampliação da área de negócios do setor externo, voltando a servir como ferramenta de expansão econômica, com o mínimo de vinculação política e ideológica. As relações com os EUA passam a conhecer numerosos pontos de tensão, tendência que se mantém inalterada e se agrava na administração Médici ${ }^{8}$.

Foi, entretanto, durante o Governo Geisel (1974-1979) que se processa o definitivo descolamento do principal eixo de constrangimento da ação internacional que o Brasil implementava há décadas para ampliar as bases de captação de recursos para o desenvolvimento. A evidência da deterioração das relações com os norte-americanos favorece o movimento reativo de construção de vínculos internacionais diversificados. Sob o nacional-desenvolvimentismo geiseliano tal movimento ganhou a melhor leitura e instrumentalização, quando moldou-se sobre objetivos pré-estabelecidos, expectativas compartilhadas com os parceiros escolhidos e linhas de ação definidas. Trata-se, no momento, de elemento pontual do grande desígnio de construir uma presença internacional própria, não condicionada pelos desígnios da potência hegemônica, com vistas a 
aumentar a capacidade de influência do país em questões globais que pudessem afetá-lo, e, notadamente, fazer face a situações de vulnerabilidade geradas pela crescente dependência de insumos externos. No quinquênio, o Brasil consolida as linhas de cooperação com a Europa Ocidental, reafirma os laços já dinâmicos com o Japão e afasta-se dos "relacionamentos excludentes”, notadamente Israel e África do Sul, que impediam uma melhor instrumentalização das relações com o Oriente Médio e com a África Negra.

O tempo das privações da década de 1980 propiciou que a constituição de parcerias pontuais atingisse a sua máxima sofisticação conceitual, exemplificada nas coalizões constituídas com alguns outros países subdesenvolvidos nos embates travados nos foros multilaterais em torno da consecução das regras do comércio internacional, e em prol do desimpedimento do acesso aos recursos da ciência e tecnologia indutores do desenvolvimento.

Durante esse longo período, tornou-se evidente que a vocação universalista e a inserção internacional multifacetada que caracterizavam (e ainda caracterizam, em grande medida) o Brasil, faziam do país um parceiro importante em muitas ocasiões. Afinal, o seu respeitável patrimônio de relações bilaterais elevava a sua capacidade de articulação em níveis multilaterais, sempre sendo possível identificar o Brasil - dentre as nações que o demandavam, tanto do ponto de vista político quanto econômico (países africanos recém-libertos, países árabes, mesmo algumas nações da América Latina, e todo o rol de nações constantes na imensa categoria de países em desenvolvimento ou subdesenvolvidos) ou dentre as nações que tinham-no como demandante (Japão, Europa Ocidental) - o parceiro ideal para ultrapassar e redimir os constrangimentos do momento.

Acresce que essa capacidade de articulação era também utilizada como capital de intermediação, ampliado pelos princípios da sua perene atuação diplomática (o seu caráter não-confrontacionista, a tradição pacifista, a busca negociada das controvérsias, a sobrevalorização da auto-determinação e da nãointervenção, o respeito ao direito). Desse modo, no período, o país utilizou esse capital, ao qual adicionou as possibilidades de acesso ao seu mercado e de obtenção de maiores margens de autonomia no processo decisório internacional, como trunfos com os quais constituir as parcerias necessárias.

\subsubsection{A vertente européia}

A expressão mais permanente, visível e recorrente do conceito de parceria estratégica na história da política exterior do Brasil manifesta-se nesse período e pode ser determinada pela disposição de fatores de aproximação - nos mais distintos aspectos e em vários momentos - existente nas relações do Brasil com a Europa Ocidental.

Esta expressão permite falar mesmo na existência de uma subjacente Vertente Européia no cálculo estratégico da diplomacia brasileira, com o que se 
pretende expressar a existência de uma disposição mútua e geral em fortalecer, em determinadas conjunturas, os laços bilaterais, a identidade de interesses e a simpatia recíproca entre alguns poucos países e o Brasil ${ }^{9}$.

Isso é tanto verdade que é possível afirmar que as relações Brasil-Europa Ocidental no século XX sejam caracterizadas por uma precisa regularidade: sempre que o Brasil procura alternativas - por vezes políticas, outras vezes econômicas ao seu relacionamento com os EUA, volta-se para a Europa Ocidental; sempre é muito bem correspondido.

Observe-se, entretanto que a Vertente Européia - da mesma forma que os interesses que o Brasil busca realizar nas interações com os seus diferentes parceiros - é multifacetada, e esconde grandes diferenças de percepção sobre as possibilidades de obter ganhos concretos no relacionamento com os diferentes países da Europa Ocidental. Pode-se estabelecer, a título de simplificação, três grandes eixos que conteriam as características mais gerais das relações do Brasil com os países da região. É bem verdade que estas linhas gerais não são estáticas, mas apenas predominantes, o que permite também afirmar que as características das relações bilaterais mudam e adaptam-se às conjunturas, permanecendo entretanto, inalteradas em sua essência no grande período que se inicia em após a segunda guerra e chega à década de 1990 . Ou seja, determinados relacionamentos podem passar de um eixo a outro, de acordo com a conjuntura. Assim, pode-se estabelecer:

a) o eixo sentimental - contém as relações do Brasil com a Espanha e Portugal, e é caracterizado pelo forte componente de simpatia entre os povos, pela identidade cultural primária e pelos grandes contingentes de imigrantes de origem, mas apresentam poucas possibilidades de realização de interesses econômicos;

b) o eixo instrumental - se compõe das relações com a Itália e com a Alemanha, também marcadas pela forte simpatia estrutural entre os povos, pela presença de contingentes de imigrantes importantes e economicamente influentes, é por definição o eixo em que historicamente se realizam os interesses brasileiros na Europa Ocidental, e são, portanto, os relacionamentos mais importantes, dinâmicos e efetivos da Vertente Européia brasileira. Não seria exagerado afirmar que as relações do Brasil com a Europa Ocidental ganham tradicionalmente instrumentalidade apenas quando examinadas sob o prisma das relações com a Itália e com a Alemanha;

c) o eixo do conflito - encerra estruturalmente as relações do Brasil com o projeto europeu de integração, que tradicionalmente oferece limitações sérias às ambições comerciais do país, tanto no âmbito regional quanto nos foros multilaterais;

d) o eixo da indiferença - é integrado pelas relações bilaterais que não encerram em si nem os limites da dependência nem a força das parcerias que proporcionam autonomia; nele vagam as sociedades que se desconhecem e os 
relacionamentos econômicos inócuos para a realização de interesses; compõem, portanto, este eixo, as relações do Brasil com os Países Escandinavos, Bélgica, Países Baixos, Reino Unido e França.

\subsection{A seletividade como qualificação principal}

A abertura do segundo período se confunde com o fim do mundo bipolar e se estende aos nossos dias. A mudança de qualidade está diretamente relacionada com as próprias transformações na ordem internacional desde então, processo certamente ainda não concluído, mas definitivamente marcado pela mudança de centralidade das relações internacionais, na qual observa-se a substituição da lógica estritamente político-militar e ideológica pela supremacia da lógica econômica (competição por mercados e por maiores espaços na economia mundial) ${ }^{10}$.

Nesta conjuntura, o Brasil é confrontado com a desproporção entre a sua universalidade de interesses e a gritante modicidade de recursos e meios disponíveis para realizá-los. À nação não resta muitas alternativas senão procurar manter abertas as suas opções internacionais, ao tempo em que concebe um novo esforço de modernização política e econômica e um novo modelo de integração aos fluxos internacionais. Assim, vê-se forçada a revisitar o seu acervo de interações internacionais em busca de novos arranjos instrumentalizáveis (novas parcerias estratégicas), uma vez que o processo de reestruturação da macroestrutura de poder passa a oferecer oportunidades invulgares para que as nações até então periféricas participem ativa e criativamente da formulação da agenda internacional.

Os constrangimentos internacionais mudaram, mas a inserção internacional do Brasil na década de 1990 segue orientada pela mesma leitura de interesse nacional: afinal, não seria razoável conceber uma alteração da resultante que dispõe a busca do desenvolvimento como norte da atuação internacional, uma vez que o Brasil ainda tem um longo caminho a percorrer no resgate das suas imensas dívidas sociais. Assim, sua ação passa também a ser matizada pela permanente vigília da estabilização econômica, pela observância dos valores da democracia representativa, pelo respeito aos direitos humanos e pelo resguardo dos recursos do meio ambiente e sua utilização em um processo de desenvolvimento sustentado, acrescidos dos tradicionais objetivos de ampliar o acesso aos mercados, às tecnologias, aos investimentos, à cooperação externa, e obter melhor participação no processo decisório, atuando para que mudem as regras de funcionamento do sistema internacional, os mecanismos decisórios e o elenco de atores válidos e reconhecidos. Os novos e velhos vértices são amplamente compatíveis com os interesses imediatos da nação e com os seus interesses globais, signifique isso a demanda por um assento permanente no Conselho de Segurança das Nações Unidas ou a articulação de novas frentes operacionais nos foros multilaterais políticos e econômicos tradicionais. 
Acresce que os novos desafios internacionais impõem ao Brasil nova maneira de se relacionar com o mundo, ou pelo menos, vão forçá-lo a precisar as linhas de uma atuação internacional condizente com os meios disponíveis. A necessidade de qualificar o universalismo com boas doses de pragmatismo, dando origem às parcerias estratégicas, deixa de ser gradualmente uma manifestação isolada de um modo particular de obtenção de recursos do meio internacional, para passar à condição de qualificação principal do modo de interação internacional do país.

Com efeito, o universalismo seletivo não encerra a velha maneira de conceber os interesses nacionais como sendo realizáveis através do relacionamento com um imenso elenco de atores internacionais (nações, organizações internacionais, projetos de integração regional), mas publicamente sagra, nesse rol, os seus vencedores - mais do que nunca, nos dias que correm, a idéia de parceria estratégica passa a ser explorada para precisar as interações que permitem ganhos substantivos numa cena internacional caracterizada pelos crescentes apertos das margens de decisão.

A rápida transição de adjetivação acessória à qualificação principal da política exterior do Brasil nos anos noventa não representa uma ruptura. Bem ao contrário, os novos temas que dominam a agenda internacional, como direitos humanos, meio-ambiente, demografia e fluxos migratórios, segurança (narcotráfico, terrorismo transnacional, a vertiginosa ascensão do crime organizado), a nãoproliferação, o exacerbamento das restrições de acesso à ciência e a tecnologia, dentre outros, impunham, desde a década de oitenta, de um lado, a necessidade de construção de alianças operacionais pautadas pela concertação política em foros multilaterais para a negociação de regimes internacionais regulatórios, e, de outro, a própria cooperação científica e tecnológica com a intenção de ultrapassar as limitações ao acesso dos insumos para o desenvolvimento.

A qualificação contemporânea de universalismo seletivo descarta o exclusivismo e as relações excludentes, mas efetivamente constrói os seus grandes eixos de atuação geográfica, que seriam:

a) o eixo regional - Caracas-Buenos Aires - é profundamente balizado pela própria ancoragem latino-americana do Brasil, significando um reforço das prioridades das relações com os países vizinhos, especialmente os da América do Sul, sendo esta a sua área de interesse imediato. Neste eixo, torna-se evidente o caráter prioritário de que se revestem as relações com a Argentina e com os demais parceiros do MERCOSUL, uma vez que já se compreende a inserção nos fluxos econômicos internacionais como sendo viável exclusivamente através dos arranjos da integração regional ${ }^{11}$;

b) o eixo norte-americano - centrado em Washington, abarca o grande projeto de integração econômica que inclui o Canadá e o México, mas pauta-se, evidentemente, sobre as relações políticas e econômicas com os EUA, principal 
cliente, fornecedor e investidor individual do Brasil. Esse eixo ganha em dinamismo a partir do início do processo de "desdramatização" das relações com os EUA, que passam a se pautar pela constituição de uma agenda bilateral positiva, inclusive para a regulação dos contencioso comercial, e para o estabelecimento de novas linhas de cooperação política .

c) o eixo europeu - baseado em Berlim, compreende, a um só tempo, as relações com a União Européia e com os países da Europa Ocidental - é o eixo tradicional da orientação de constituição de parcerias estratégicas. No presente, as relações com esse eixo pautam-se pelas tentativas de tornar as relações bilaterais, com os diversos parceiros da região, ainda mais densas, e de perenizar as relações com a União Européia, tornando-as menos vulneráveis às injunções conjunturais de otimismo ou pessimismo que frequentemente assolam as expectativas gerais acerca dos rumos da Europa Unida.

Maior e mais completo projeto de integração regional do mundo contemporâneo, a União Européia surge na década de noventa como elemento fundamental para uma nova definição do velho movimento brasileiro de diversificar seus vínculos internacionais para ampliar a sua liberdade de manobra, agora redimensionado mediante a configuração de novo interesse dos EUA pela América Latina, o que certamente impõe ao Brasil necessária dose de cautela nos intrincados arranjos que se avizinham com a configuração das negociações acerca da Área de Livre Comércio das Américas - ALCA. Nesse caso, trata-se de resguardar o potencial de irradiação global que têm o Brasil e o MERCOSUL mediante o equilíbrio da relação de forças no tabuleiro econômico e político regional com a atração de capitais europeus e com o fortalecimento dos instrumentos de cooperação política entre o MERCOSUL e a União Européia ${ }^{12}$.

c) o eixo da Orla do Pacífico - evidentemente centrado sobre Tóquio, compreende a clara disposição de reforçar os laços tradicionais de cooperação econômica e científico-tecnológica com o Japão e de iniciar a intensificação gradual da cooperação com os demais países da região (Coréia do Sul, Taiwan, Cingapura, Tailândia, etc ${ }^{13}$, apesar da crise econômica de matiz financeiro que assola no momento a região .

d) o eixo das potências regionais - é multicentrado nos ângulos do quadrilátero Pequim-Moscou-Nova Dheli-Pretória, e encerra realidades políticas diversas e níveis de cooperação distintos. Estas são relações estabelecidas com países com os quais o Brasil mantém inúmeras afinidades, uma vez que as nações enfrentam os mesmos tipos de problemas no cenário internacional, além de desempenharem o mesmo papel protagônico de potências regionais ${ }^{14}$.

As relações com a China Popular, que tem se incrementado desde a década de oitenta, com a cooperação em setores de infra-estrutura, energia, matérias primas, e indústria pesada, e, mais recentemente, na área espacial, constituem grande promessa, a se considerar a potencialidade do mercado consumidor 
chinês, sendo, portanto, aposta de futuro do ponto de vista da política exterior do Brasil.

As relações com a Índia são igualmente favorecidas pelo passado recente de cooperação política nos fóruns multilaterais, sobretudo na agenda de regulação do comércio internacional, esperando-se uma maior dinamização da potencialíssima cooperação científica e tecnológica.

As relações com a Rússia, igualmente muito mais marcadas pelas suas potencialidades do que pelas suas efetividades, prometem linhas de cooperação econômica, científica e tecnológica bastante expressivas, na área das tecnologias de ponta na área de novos materiais e energia e de capacitação no savoir faire capitalista ${ }^{15}$.

Finalmente, as relações com a África do Sul, retomadas após a redemocratização do país com o fim do regime segregacionista do apartheid, assumem importância estratégica de relevo para o Brasil, uma vez que, considerando-se ser esta a fronteira atlântica natural do cone sul americano, para ela convergem os esforços de cooperação na área da segurança, além de se abrirem boas oportunidades de cooperação nos investimentos recíprocos na exploração mineral e agropecuária ${ }^{16}$.

\section{A universalidade como circunstância - à guisa de conclusão}

A universalidade, a credibilidade política, a expressividade econômica, a capacidade de atração cultural, patrimônio longamente consolidado ao longo da história da política exterior do Brasil, permitiram a preparação da nação para atuar como ator global, papel protagônico que permite a veiculação de seu escopo civilizacional e de sua "visão de mundo". Este papel, paulatinamente ensaiado ao longo das últimas décadas, consagra justamente o "mundo" como seu cenário, e estabelece como suas falas diuturnas "um mundo a ganhar, o mundo a fazer".

O advento do universalismo seletivo, em suas duas vertentes históricas, identificadas com tempos distintos (como válvula de escape e como qualificação da inserção internacional), é uma estratégia para fazer sobreviver a universalidade como princípio, conferindo-lhe instrumentalidade para a obtenção de recursos do meio internacional (sejam insumos para os projetos de desenvolvimento, sejam maiores margens de autonomia). Tal processo se reveste de transcendência estratégica na década de noventa, quando os altos níveis de plasticidade da cena internacional permitem o rearranjo das configurações tradicionais do poder mundial e a tomada de posições mais vantajosas (ou menos prejudicadas) para países intermediários como o Brasil.

Sob este ângulo, portanto, a seletividade não pode ser confundida como auto-limitação da presença internacional, perda de lugares ou posições, mas como estratégia de racionalização dos contatos bilaterais que efetivamente permitirão 


\section{minorar os custos políticos e econômicos necessários para contornar os constrangimentos internacionais da hora e galgar posições de relativo conforto para a realização do interesse nacional}

A seletividade, ao proporcionar instrumentalidade ao universalismo, renova-lhe a permanência no rol dos princípios e valores que orientam a Política Exterior, conferindo-lhe o revestimento de preponderância para a inserção internacional do país contemporâneo, expresso em sua perene oração para o futuro: enfim, o mundo como vocação, a universalidade como circunstância.

\section{Notas:}

1 Sugere-se uma revisão da vasta coleção de artigos publicados ao longo dos quarenta anos da Revista Brasileira de Relações Internacionais, o que certamente permitirá aos interessados obter um painel geral do sistema de relações bilaterais do Brasil. Além disso, uma alentada bibliografia construída sobre a pesquisa de fundo histórico começa a compor conceitualmente o quadro das parcerias históricas do Brasil. Ver, por exemplo, CERVO, Amado L. As relações históricas entre o Brasil e a Itália: o papel da diplomacia. Brasília: EDUNB, 1992, 261 p.; da lavra de Moniz Bandeira, ver BANDEIRA, L. A. Moniz. Brasil-Estados Unidos: a rivalidade emergente (1950-1988). Rio de Janeiro: Civilização Brasileira, 1989, 328 p.; O milagre alemão e o desenvolvimento do Brasil: as relações da Alemanha com o Brasil e a América Latina (1949-1994). São Paulo: Ensaio, 1994, 246 p.; Estado Nacional e Política Internacional na América Latina: o continente nas relações Argentina-Brasil (1930-1992). Brasília/São Paulo: EDUNB/Ensaio, 1993, 304 p.; SARAIVA, José Flávio S. O lugar da África: a dimensão atlântica da política externa brasileira (de 1946 a nossos dias). Brasília: EDUNB, 1996, 280 p. Para uma completa composição deste vasto painel, aguarda-se a conclusão dos estudos já em elaboração acerca das relações do Brasil com Portugal, com o Reino Unido e França. Constituem ainda lacunas sérias as relações do Brasil com o Japão, Espanha, Santa Sé, Rússia e com o projeto europeu de integração, bem como uma atualização dos estudos acerca das relações brasileiro-norteamericanas.

2 CERVO, Amado L. Relações Internacionais do Brasil, in: CERVO, Amado L. (org.). O desafio internacional: a política exterior do Brasil de 1930 a nossos dias. Brasília: EDUNB, 1994, 359 p.

3 LESSA, Antônio Carlos. “A estratégia de diversificação de parcerias no contexto do Nacionaldesenvolvimentismo (1974-1979)”. Revista Brasileira de Relações Internacionais, 38(1):24-39 (1995).

4 Ver, dentre outros, BANDEIRA, L. A. Moniz. A rivalidade emergente, Op. Cit.

5 MALAN, Pedro S. As relações econômicas internacionais do Brasil (1945-1964). In: FAUSTO, Boris (org.). História Geral da Civilização Brasileira. São Paulo: DIFEL, vol. 11, p. 51-106.

6 SILVA, Alexandra de Mello. A Política Externa de JK: a Operação Pan-Americana. Rio de Janeiro: FGV/ CPDOC, mimeo, 1992.

7 SARAIVA, José Flávio S. Do silêncio à afirmação: as relações do Brasil com a África. In: CERVO, Amado L. (org.). Op. Cit. ; sobretudo, do mesmo autor, O lugar da África, Op. Cit.

8 BANDEIRA, L. A. Moniz. Continuidade e mudança na Política Externa Brasileira. Revista Brasileira de Política Internacional , 29(115-116):91-110 (1986), p. 91-92.

9 A propósito, ver LESSA, Antônio Carlos M. Brasil, Estados Unidos e Europa Ocidental no contexto do nacional-desenvolvimentismo: estratégias de diversificação de parcerias (1974-1979). Brasília: Universidade de Brasília, dissertação de mestrado, 118 p., 1994.

${ }^{10}$ Ver LAFER, Celso \& FONSECA Júnior, Gelson. Questões para a diplomacia no Contexto Internacional das Polaridades Indefinidas (notas analíticas e algumas sugestões). In: FONSECA Júnior, Gelson \& CASTRO, Sérgio Henrique Nabuco de (orgs.). Temas de Política Externa Brasileira II. Brasília/São Paulo: FUNAG/ Paz e Terra, 1994, vol. 1, p. 49-77.

11 A propósito, ver, além da vasta biliografia acerca da constituição do MERCOSUL e de outros aspectos das relações do Brasil com a Argentina, GUIMARÃES, Samuel P. (org.). Brasil e Venezuela: esperanças e determinação na virada do século. Brasília: FUNAG/IPRI, 1995, 225 p.

12 ABDENUR, Roberto. Mercosul, ALCA, União Européia - Reflexões para uma estratégia brasileira. Política Externa, 6(2): 62-70 (1997). 
${ }^{13}$ Mantém-se, de fato, uma parceria muito importante com o Japão, calcada sobre laços históricos de vulto, profundamente dinamizada pela presença de comunidades de origem: o Brasil abriga mais de um milhão de habitantes de origem nipônica, ao tempo em que mais de 150 mil brasileiros ganham a vida no Japão.

${ }^{14}$ Ver PRATES, Alcides G. R. O Brasil e a coordenação entre os países de porte continental numa perspectiva atual. Revista Brasileira de Política Internacional, 39(2):33-50 (1996).

${ }^{15}$ HIRST, Mônica \& PINHEIRO, Letícia. A política externa do Brasil em dois tempos. Revista Brasileira de Política Internacional, 38(1):5-23 (1995).

${ }^{16}$ GUIMARÃES, Samuel P. (org.). Brasil e África do Sul: riscos e oportunidades no tumulto da globalização. Brasília: FUNAG/IPRI, 1996, 896 p. 